\title{
A Design Challenge - Incorporating Design into the First Year Engineering Curriculum
}

\author{
Scott B. Nokleby and Remon Pop-Iliev \\ Faculty of Engineering and Applied Science \\ University of Ontario Institute of Technology \\ 2000 Simcoe Street North \\ Oshawa, ON L1H $7 K 4$ \\ CANADA \\ scott.nokleby@uoit.ca \\ remon.pop-iliev@uoit.ca
}

\begin{abstract}
This paper outlines a novel engineering graphics and design course at the University of Ontario Institute of Technology (UOIT). The course is designed to enable first year engineering students to learn the engineering design process while at the same time developing strong free-hand sketching and 3-D solid modelling skills. The dual nature of the graphics-design course enables students to learn engineering graphics in a non-isolated manner. The results after two years of offering the course show that first-year team-based projects are feasible and manageable and that first-year engineering students are capable of completing rather complex and innovative solid modelling design projects.
\end{abstract}

\section{Introduction}

The University of Ontario Institute of Technology (UOIT), located in Oshawa, Ontario, is the first new university in the province in over 40 years. UOIT accepted its first students in September, 2003.

The Faculty of Engineering and Applied Science along with its affiliated School of Energy Systems and Nuclear Science offers engineering degrees in the following areas:

\author{
Automotive Engineering \\ Electrical Engineering \\ Energy Systems Engineering \\ Manufacturing Engineering \\ Mechanical Engineering (three variations) \\ - Comprehensive \\ - Energy Engineering Option \\ - Mechatronics Engineering Option \\ Nuclear Engineering \\ Software Engineering
}

Manufacturing and Nuclear Engineering started in 2003, followed by Mechanical and Energy Systems Engineering in 2004. Automotive, Electrical, and Software will be starting in 2005. This paper focuses on the mechanically oriented programs: Automotive, Manufacturing, and Mechanical Engineering at UOIT.

As a new university, UOIT offers a unique opportunity to develop its programs to incorporate best practices in terms of teaching engineering students. As such, one of the key features in the mechanically oriented engineering programs is the heavy emphasis placed on design in the curricula.

In recent years, the trend has been to introduce engineering students to the basic concepts of design at an early stage combined with an emphasis on design throughout the curriculum [1]. To meet this challenge, the authors of this paper are actively implementing a comprehensive design strategy at UOIT. This involves the development of design engineering curricula and design laboratories for the Automotive, Mechanical, and Manufacturing programs.

The NSERC Chairs in Design Engineering state that "Providing a design continuum is critical" [2]. As a result of this need, UOIT's current engineering curricula in the mechanically oriented programs include a continuum of design engineering courses of a general nature which have increasing levels of difficulty so as to match the pace at which students grasp engineering knowledge:

- Year 1: Engineering Graphics and Design

- Year 2: Concurrent Engineering and Design

- Year 3: Computer-Aided Design

- Year 4: Design Thesis 
The above general courses are complemented with a variety of program-specific design engineering courses:

- Automotive Component Design

- Automotive Systems Design

- Machine Design

- Manufacturing Systems Design

- Mechanical Systems Design

- Mechatronic Systems Design

- Thermofluids and Energy Systems Design

The key to implementing this continuum design strategy is to successfully introduce first year engineering students to the basic concepts of design in order to provide them with a solid foundation upon which they can build their design skills and expertise. At UOIT this is done in the first year, first semester course, ENGR 3200U: Engineering Graphics and Design.

ENGR $3200 \mathrm{U}$ is taken by all students in the Automotive, Energy Systems, Manufacturing, Mechanical, and Nuclear Engineering programs. The design challenge faced was to create a course that taught students who have no background in engineering, the basics of the engineering design process. In addition, students who successfully complete the course must have a comprehensive understanding of engineering graphics, including free-hand sketching and 3-D solid modelling.

\section{Course Description and Structure}

ENGR 3200U is taught over a 13 week period in the first semester of first year. Students attend three hours of lectures, one-and-half hours of tutorials, and one-and-half hours of laboratories per week.

The UOIT Calendar course description for ENGR 3200U reads:

Engineering drawing techniques,
dimensions and geometric tolerances,
standard viewpoints and section planes,
orthographic projections, use of 3-D solid
modelling and CAD software (and possibly
other design and graphics software); a case-
based introduction to engineering design;
use of graphics and illustrations in
engineering design; design projects by
individuals and groups; basics of project
management, such as organizing, planning,
scheduling and controlling; application of
such computer tools as spreadsheets, project
management software, computer-aided
drafting and design tools.

As can be seen from the description, a great deal of material, from traditional engineering graphics to 3-D solid modelling to engineering design, are all covered in this one semester course. The wide range of the course necessitated the use of three different textbooks: one to cover graphics [3]; one to cover design [4]; and one to be used in the laboratories to cover solid modelling [5].

Students are assessed through a combination of problem sets, labs, tests, midterm exam, group design project, and final exam.

In roughly the first half of the course, students cover graphics. Lectures are used to present the theory of engineering graphics while at the same time emphasizing the importance of graphics in the design process. A heavy emphasis is placed on free-hand sketching.

The laboratories are used to teach the students the use of a commercial 3-D solid modelling package. Engineering programs are moving away from using 2-D CAD packages in favour of 3-D solid modelling packages that are now common place in industry. Currently, SolidWorks ${ }^{\circledR}$ is used as the CAD package in first and second year at UOIT.

To enhance the students learning, every engineering student at UOIT has a laptop computer that is equipped with a suite of software, including SolidWorks ${ }^{\circledR}, \quad$ Microsoft Project ${ }^{\circledR}, \quad$ Microsoft Office ${ }^{\circledR}$, and MATLAB ${ }^{\circledR}$. The laptops are connected to a wireless network that enables students to easily work together on group projects.

Students gain a great deal of exposure into using a powerful CAD package as a tool in designing a product. An emphasis is placed on using the CAD package not only for creating engineering drawings, but for visualizing design ideas through virtual prototyping and motion simulation.

The tutorials in the course are used to reinforce the topics learned in both the lectures and laboratories. Tutorials in the first half of the course alternate each week between having the students practice fee-hand sketching and further practice using the CAD package.

Although the students learn how to use a commercial CAD package, the authors of this paper firmly believe that it is critical for engineering students to be able to free-hand sketch. 3-D CAD packages are only useful if a person can visualize a design in their head. By putting an emphasis on freehand sketching in the tutorials, problems sets, tests and exams, the students are able to develop their 3-D visualization skills. The ability to visualize ideas spatially is critical for an engineer to be a successful designer. 
The second half of the course focuses on the design process. Students learn the basic design process including: product planning; identifying customer needs; product specifications; concept generation; concept selection; and concept testing. In addition students are introduced to the basics of design for manufacturing and robust design.

The laboratories in the second half of the course continue to focus on teaching SolidWorks ${ }^{\circledR}$. However, one lab is used to introduce the students to using project planning software, namely, Microsoft Project ${ }^{\circledR}$.

The tutorials in the second half of the course alternate between design case studies, group design project work, and additional CAD practice.

The course culminates in the group design project. This project is started roughly half-way through the course and encapsulates all the knowledge the students have gained during the course.

\section{Group Design Project}

The centre piece of the course is the group design project. ENGR $3200 \mathrm{U}$ puts an emphasis on teamwork, a skill that first year students need to develop. The project allows the students to combine the knowledge that they have gained in both graphics and design to create a solution to a real-world design problem.

Students work collaboratively to provide required design engineering deliverables. Students have to take an existing design and redesign it to include three independent innovative enhancements to the existing design's functionality. As structured, the group design project includes both a reverse engineering component and a creative design segment.

The requirements for the project force the students to go through a structured design process. Students must submit details of their concept generation and concept selection processes, along with a complete set of engineering drawings of their final design, including assembly drawings, detail drawings, and bill of materials. In addition, students must create a short manual for their design and give an oral presentation on their final design. All of the materials must be submitted in the form of a technical report.

The above requirements for the project force the students to utilize their free-hand sketching abilities by making them document their concept generation process. The complete set of working drawings requires the students to utilize their newly acquired CAD skills.
The project also reinforces the "soft skills" that students need to learn and practice, including teamwork, technical writing, presentation skills, and time management.

As mentioned previously, the design challenge faced by the authors was to create a course that teaches engineering design to students who have yet to be exposed to other basic engineering courses. To meet this design challenge, the project and its requirements were designed to emphasize the design process and the ability to come up with conceptually feasible designs, not on performing engineering calculations.

Students are encouraged to create a realistic design, i.e., the design should logically meet the desired requirements, but the students are not asked to produce engineering calculations to verify that the design does meet those requirements.

For the first two years of offering the course, students were assigned the task of modifying a folding handcart in order to meet three new design requirements:

Requirement 1: The new multifunctional handcart should be easily convertible into a chair that would accommodate a single average person while loaded to its full capacity.

Requirement 2: The new multifunctional handcart should be convertible into a small ladder when not loaded and when not used for carrying.

Requirement 3: The new multifunctional handcart should be equally usable on dry and snow-covered pathways when loaded to its full capacity.

The groups were allowed to modify an existing handcart design through reverse engineering or create a wholly new design.

The project deliverables included:

- A complete set of engineering drawings describing completely the newly designed or redesigned handcart with the three new features. Included in this package was the requirement for a 3-D assembly with motion functionality and 3-D and respective 2-D multiview drawings of all subassemblies, components, and parts including dimensions, tolerances, and bills of materials using SolidWorks ${ }^{\circledR}$ in sufficient detail so that a remotely located manufacturer would be able to produce it without further intervention. 
- A single-page (three columns, landscape orientation on a letter size paper, both sides printed) Owner's Manual/Technical

Specification/Brochure describing the product including, for example, rendered SolidWorks ${ }^{\circledR}$ assembly drawings.

- A five minute Microsoft PowerPoint ${ }^{\circledR}$ supported oral presentation of the project in front of the class.

- Technical report with literature survey, outline of design process followed, and discussion of the final design.

A hard copy as well as an electronic copy of all materials was required to be submitted.

\section{Results}

Figures 1 to 7 are examples of the quality of work that first year engineering students can achieve.

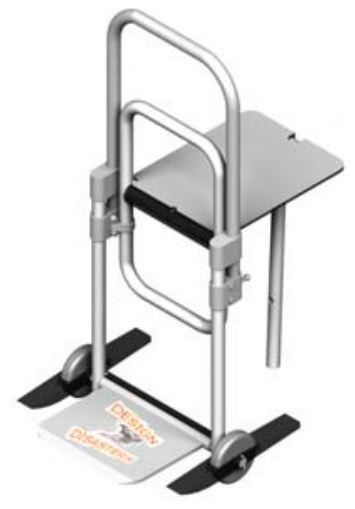

Figure 1. Example of first year student work (Courtesy: Eric Dillane, Mike Fisher, Simon Freijer-Poulsen Cloutier, and Kevin Taillieu)

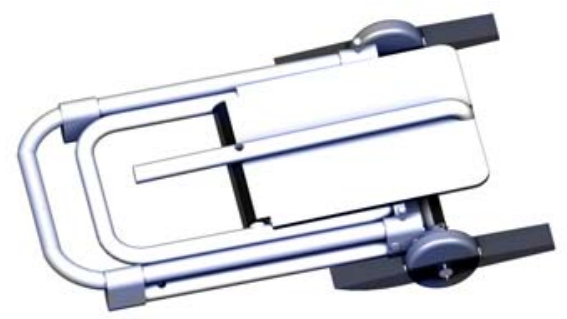

Figure 2. Example of first year student work (Courtesy: Eric Dillane, Mike Fisher, Simon Freijer-Poulsen Cloutier, and Kevin Taillieu)

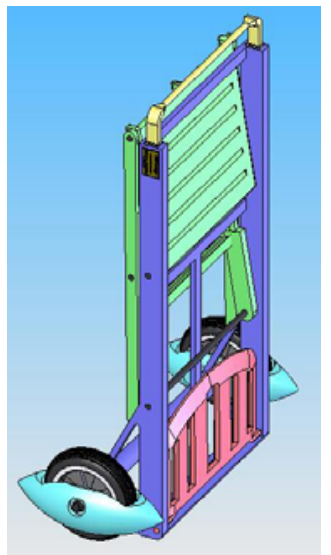

Figure 3. Example of first year student work (Courtesy: Matt Cannon, Geoff Chadsey, Cameron Mackey, and Mike Reed)

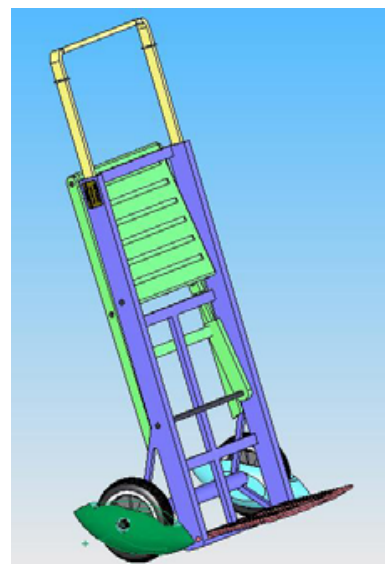

Figure 4. Example of first year student work (Courtesy: Matt Cannon, Geoff Chadsey, Cameron Mackey, and Mike Reed)

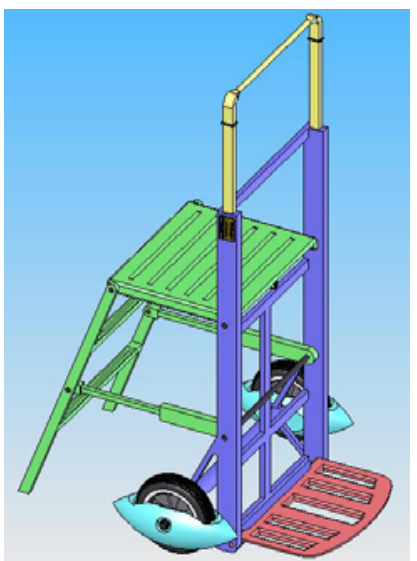

Figure 5. Example of first year student work (Courtesy: Matt Cannon, Geoff Chadsey, Cameron Mackey, and Mike Reed) 


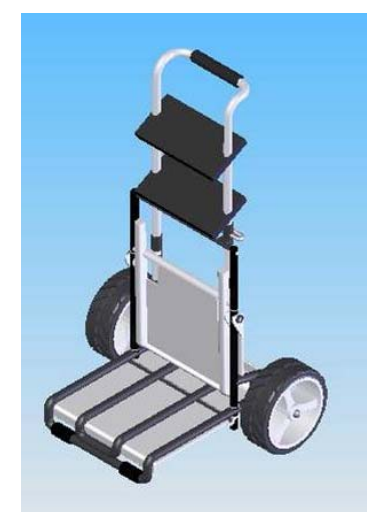

Figure 6. Example of first year student work (Courtesy: Tom Cadieux, Jia Ming Liang, Neil Lovitt, Jason Tang, and Hadi Turk)

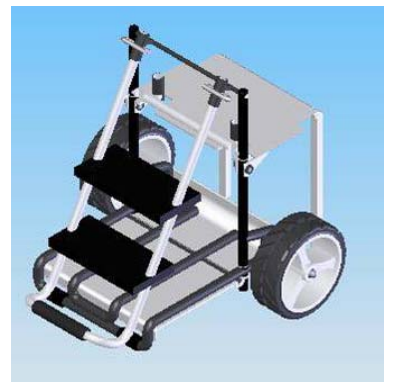

Figure 7. Example of first year student work (Courtesy: Tom Cadieux, Jia Ming Liang, Neil Lovitt, Jason Tang, and Hadi Turk)

After two years of offering the course, the results have shown that the group project has a number of benefits.

First, the project reinforces with the students the need to follow a structured design process.

Second, it allows students to learn engineering graphics in a non-isolated manner. Instead of working on drawings that have no context, the students work on drawings related to their design.

Third, the design project allows the students to practice other important "soft skills" such as teamwork, technical writing, and presentation skills.

In terms of students using the laptop, the fact that every student has unrestricted access to SolidWorks ${ }^{\circledR}$ and the other software packages opens up all sorts of possibilities in terms of computer-based assignments and novel content delivery that reinforces the desired learning outcomes. In addition, students do not have to waste time waiting to access a limited number of CAD seats found at other institutions. The necessary tools are at their finger tips, both on campus and off campus.

The laptop usage does have some drawbacks. First, the yearly laptop cost is high, making it another financial cost for students to incur. Second, it can be a challenge to keep students attention when they have a computer connected to the internet in front of them during lectures. However, the benefits of having ubiquitous computer access to state-of-the-art engineering software, far out weighs these negatives.

As a new course, and for any course for that matter, there are areas that can be improved. One area that needs improvement is assessing the students' CAD skills. Currently, students are assessed on their CAD skills through the assignments, labs, and project. This makes it difficult to ensure that the students are learning how to use the CAD package and are not just copying files from their fellow classmates. To counter this, for the next offering of the course, one test will be dedicated to assessing the students' CAD skills.

Another area that can be improved is the integration of the use of project planning software into the group design project. Currently, the students perform one project planning laboratory assignment using Microsoft Project ${ }^{\circledR}$ near the end of the course. This lab will be moved to the middle of the course to roughly the same time that the project is introduced. The students will be required to submit a project plan using the project planning software at the start of the project indicating a timeline for completion of the project and its deliverables. It is hoped that this change will further reinforce with the students the need for a project plan and will help the students learn better time management skills.

Overall, the results of the course and particularly the group design project have demonstrated that firstyear team-based projects are feasible and manageable and that first-year engineering students are capable of completing rather complex and innovative solid modelling design projects.

The combination of a course with both graphics and design as emphasises works well together. The two topics complement each other. Design is the process of creating something novel and graphics is the language of that process.

Likewise the combination of emphasizing both free-hand sketching and 3-D solid modelling has worked well. By creating assignments where students first have to free-hand sketch an object, then draw the same object using a 3-D CAD package, and then compare the free-hand sketch to the 3-D model and correct any discrepancies between the two is a powerful methodology for improving both their sketching and 3-D solid modelling skills.

\section{Further Considerations}

As mentioned previously, ENGR $3200 \mathrm{U}$ is the first course in a continuum of general design courses in the mechanically oriented programs at UOIT. The second course in this continuum is the second year 
course ENGR 2310U: Concurrent Engineering and Design. As the title suggests, students in this course learn the modern concurrent design process. Students build upon the design, graphics, solid modelling, and soft skills developed in ENGR 3200U. ENGR 2310U makes heavy use of solid modelling in the form SolidWorks ${ }^{\circledR}$, so it is critical that the students have developed strong solid modelling skills from ENGR 3200U. A detailed discussion of ENGR 2310U can be found in [6].

The next course in the continuum is ENGR 3030: Computer-Aided Design. This course builds upon both ENGR 3200U and ENGR 2310U. Unlike traditional computer-aided design courses, the computer-aided design course at UOIT is designed to not only teach how CAD packages work, but is designed to introduce students to the proper use of modern computer-aided design tools such as Finite Element Analysis (FEA) and optimization. At the same time students migrate from using SolidWorks ${ }^{\circledR}$ to using the more powerful Unigraphics NX3 ${ }^{\circledR}$.

The idea behind the change from using SolidWorks ${ }^{\circledR}$ in years one and two to using Unigraphics $N X 3 \AA$ in years three and four is to provide the students exposure to a variety of CAD packages. In addition, Unigraphics $\mathrm{NX} 3{ }^{\circledR}$ offers a variety of powerful integrated CAE (computer-aided engineering) packages.

The continuum of general courses is topped by the fourth year course ENGR 4999U: Design Thesis. In this course, under the supervision of a faculty member, students undertake a design project in their relevant field.

This continuum of general design courses is complemented with a variety of program-specific design engineering courses: Automotive Component Design, Automotive Systems Design, Machine Design, Manufacturing Systems Design, Mechanical Systems Design, Thermofluids and Energy Systems Design, and Mechatronic Systems Design. The Automotive, Manufacturing, Mechanical, Mechatronic, and Thermofluids and Energy and Systems Design courses are all program specific courses where students work in small groups on a design project related to their field, similar to the capstone project course found in most other university engineering programs.

\section{Conclusions}

A novel engineering graphics and design course has been developed at the University of Ontario Institute of Technology (UOIT). The course is designed to enable first year engineering students to learn the design process while at the same time developing strong free-hand sketching and 3-D solid modelling CAD skills. The centre piece of the course is the group design project. The results have shown that first-year team-based projects are feasible and manageable and that first-year engineering students are capable of completing rather complex and innovative solid modelling design projects.

\section{Acknowledgements}

The authors would like to thank the following UOIT students for allowing their work to be showcased in this paper: Tom Cadieux, Matt Cannon, Geoff Chadsey, Eric Dillane, Mike Fisher, Simon Freijer-Poulsen Cloutier, Jia Ming Liang, Neil Lovitt, Cameron Mackey, Mike Reed, Kevin Taillieu, Jason Tang, and Hadi Turk.

\section{References}

[1] Britton, R., Charron, F., Dickinson, T., Little, P., and Stiver, W., 2004, "Design Sequence Experiences: A Panel Discussion," in Proceedings of the Inaugural CDEN Design Conference, July 29-30, Montreal, QC, 7 pages.

[2] Angeles, J., Britton, R., Chang, L., Charron, F., Gregson, P., Gu, P., Lawrence, P., Stiver, W., Strong, D., Stuart, P., and Thompson, B., 2004, "The Engineering Design Competency," in Proceedings of the Inaugural CDEN Design Conference, July 29-30, Montreal, QC, 7 pages.

[3] Bertoline, G. R., and Wiebe, E. N., 2005, Fundamentals of Graphics Communication - Fourth Edition, McGraw-Hill: Toronto, ON.

[4] Ulrich, K. T., and Eppinger, S. D., 2004, Product Design and Development - Third Edition, McGrawHill: Toronto, ON.

[5] Planchard, D. C., and Planchard, M. P., 2004, SolidWorks 2004 Tutorial and Multimedia CD, SDC Publications: Mission, KS.

[6] Pop-Iliev, R., and Nokleby, S. B., 2005, "Concurrent Approach to Teaching Concurrent Design Engineering," to appear in Proceedings of the Second CDEN International Conference on Design Education, Innovation, and Practice, July 18-20, Kananaskis, AB. 